\title{
A remarkably simple $\alpha$-oximation of ketones to 1,2-dione monooximes using the chlorotrimethylsilane-isoamyl nitrite combination
}

\author{
Abdulkarim H. A. Mohammed ${ }^{\dagger}$ and Gopalpur Nagendrappa* \\ Department of Chemistry, Bangalore University (Central College Campus), Bangalore 560001, India
}

Received 18 November 2002; revised 15 January 2003; accepted 24 January 2003

\begin{abstract}
Ketones undergo $\alpha$-oximation by $\mathrm{NOCl}$ formed in situ from $\mathrm{Me}_{3} \mathrm{SiCl}$ and isoamyl nitrite, either in solution or under solvent-free conditions, to produce 1,2-dione monooximes in excellent yields. The oximation is regiospecific in appropriate cases. (C) 2003 Published by Elsevier Science Ltd.
\end{abstract}

$\mathrm{R}_{3} \mathrm{SiX}$ reagents, according to Fleming's analysis, react analogously to, but more selectively than HX. ${ }^{1,2}$ Treating chlorotrimethylsilane (TMSCl) with isoamyl nitrite (AmONO) is an effective method for the in situ generation of $\mathrm{NOCl}$ in aprotic solvent media as well as under solvent free conditions. We have shown earlier that $\mathrm{NOCl}$ thus produced adds to vinylsilanes in a regiospecific and stereoselective manner. ${ }^{3}$ This, to our knowledge, is the most convenient method for the generation and reaction of $\mathrm{NOCl}$ particularly for laboratory scale preparations. Conventional procedures for obtaining $\mathrm{NOCl}$ under anhydrous condition are rather cumbersome. ${ }^{4}$

The direct $\alpha$-oximation of ketones, esters, and aldehydes by $\mathrm{NOCl}$ is known. ${ }^{4 a}$ Rasmussen and Hassner argue that the methods used are associated with many shortcomings and showed that silylenol ethers are superior for achieving better yields and selectivity. ${ }^{5,6}$ However, the handling of silylenol ethers needs special care, and their preparation is an avoidable extra step. Therefore, earlier procedures are preferred even now for the preparation of $\alpha$-oximino ketones. ${ }^{7}$

$\alpha$-Oximino ketones find many applications. They are used as starting compounds for the synthesis of imidazoles, ${ }^{7}$ oxazoles, ${ }^{8} \alpha$-amino acids and esters, ${ }^{4} \alpha$-amino alcohols, ${ }^{9}$ pharmaceutically useful heterocycles ${ }^{10}$ like luciferin analogues, ${ }^{11}$ and other valuable products. $^{12}$

Keywords: oximation; TMSCl; amyl nitrite; 1,2-diketone monooxime; $\mathrm{NOCl}$.

* Corresponding author. E-mail: nagendrappa@vsnl.net

${ }^{\dagger}$ On leave from Sana’a University, Sana'a, Yemen.
There is much patent literature describing the preparation of $\alpha$-oximino ketones and their conversion to dioximes. $\alpha$-Oximino ketones hydrolyze to synthetically

Table 1. $\alpha$-Oxidation of ketones using TMSCl-AmONO

Entry




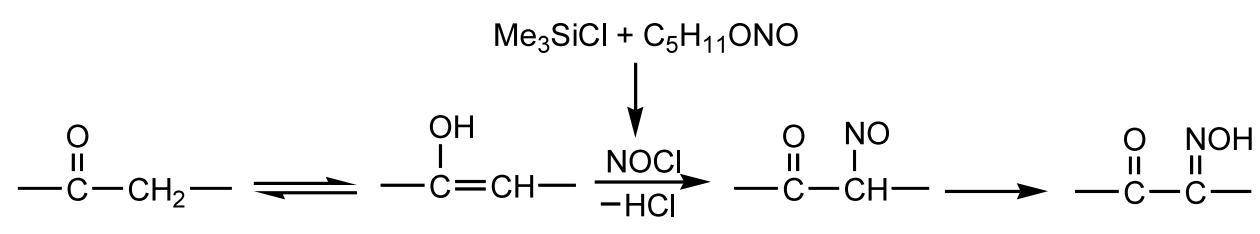

Scheme 1.

important $\alpha$-diketones, ${ }^{13}$ and serve as ligands for transition metal complexes. ${ }^{14}$

We have found that ketones undergo $\alpha$-oximation readily on treatment with TMSCl and AmONO in solvents or under solvent-free conditions. The results are reported.

$\alpha$-Oximation was carried out with aryl alkyl ketones 1-6, alkyl ketones 7-9, and the cyclic ketone 10. One molar equivalent of $\mathrm{TMSCl}$ was added to the substrate (either neat or in $\mathrm{CH}_{2} \mathrm{Cl}_{2}$ solution) at $-20^{\circ} \mathrm{C}$, followed by the dropwise addition of an equivalent quantity of isoamyl nitrite. The reaction was found to be instantaneous, but the mixture was stirred for an additional period of $30 \mathrm{~min}$ before working up. The products were purified on a silica gel column using 5\% ethyl acetate in petroleum ether (bp $45-55^{\circ} \mathrm{C}$ ) as eluant, and identified by their mp, IR, ${ }^{1} \mathrm{H}$ and ${ }^{13} \mathrm{C}$ NMR spectra, which were compared with literature data. The $\alpha$-ketooxime 18, because of its reduced stability, was isolated as a dioxime by reacting with $\mathrm{NH}_{2} \mathrm{OH} \cdot \mathrm{HCl}$. The results are given in Table 1.

The reactions run in the absence of solvent were found to give slightly better yields (about $2-5 \%$ more) than those from reactions run in solution. This observation makes the procedure particularly attractive because of its eco-friendly character. ${ }^{15}$

The oximation is brought about by $\mathrm{NOCl}$ formed in situ as shown previously by the reaction of $\mathrm{Me}_{3} \mathrm{SiCl}$ with isoamyl nitrite. ${ }^{3}$ It is to be noted that only one $\alpha$-position of the ketones $\mathbf{7 - 1 0}$ is oximated, though both are susceptible, and that monooximation occurs regiospecifically in 7 and 9 on the more readily enolizable $\alpha$-position. This indicates that the reaction starts with enolization (facilitated by $\mathrm{TMSCl} / \mathrm{HCl}$ ), and follows the route depicted in Scheme 1.

In conclusion, $\alpha$-ketooximes can be prepared from ketones in a very simple manner. The reaction can be run on preparative scale. ${ }^{16}$ No extra precaution was needed except to avoid the entry of moisture. This work discloses a new application of the organsilicon reagent, $\mathrm{Me}_{3} \mathrm{SiCl}$, for an important organic transformation.

\section{Acknowledgements}

A.H.A.M. thanks ICCR, New Delhi, for a fellowship under Cultural Exchange Programme. The work was partly supported by UGC-DRS and UGC-COSIST programmes, New Delhi. Some equipment used for the work is a donation to G.N. by the Alexander von Humboldt Foundation, Germany.

\section{References}

1. Fleming, I. Chem. Soc. Rev. 1981, 10, 83.

2. For excellent reviews on silicon-based reagents, see: (a) Brook, M. A. Silicon in Organic, Organometallic, and Polymer Chemistry; Wiley: New York, 2000; p. 189; (b) Colvin, E. W. Recent Synthetic Applications of Organo Silicon Compounds; Rappoport, Z.; Apeloig, Y., Ed.; Wiley: New York, 1988; Vol. 2, Chapter 28, p. 1667.

3. Mallya, M. N.; Nagendrappa, G.; Prasad, J. S.; Sridhar, M. A.; Lokanath, M. K.; Begum, N. S. Tetrahedron Lett. 2001, 42, 2565.

4. (a) Touster, O. Org. React. 1953, 7, 327; (b) Hassner, A.; Heathcock, C. J. Org. Chem. 1964, 29, 1350.

5. Rasmussen, J. K.; Hassner, A. J. Org. Chem. 1974, 39, 2558.

6. It is claimed that a general method using $t$-butyl thionitrate has been developed. It seems, however, to apply only to microscale preparations, since preparative TLC was used for product separation. See: Kim, Y. H.; Park, Y. J.; Kim, K. Tetrahedron Lett. 1989, 30, 2833.

7. (a) Jiang, L.; Davison, A.; Tennant, G.; Ramage, R. Tetrahedron 1998, 54, 14233. They have prepared $\mathrm{PhCOCHNOH}$ from $\mathrm{PhCOCH}_{3} \quad(40 \%$ yield $)$ and $\mathrm{PhCOCH}(\mathrm{NOH}) \mathrm{CH}_{3}$ from $\mathrm{PhCOCH}_{2} \mathrm{CH}_{3}$ by old methods; (b) Hossbach, R.; Lettau, H.; Nuhn, P.; Schneider, R.; Stenger, P.; Stiebitz, B. Pharmazie 1991, 46, 412.

8. Kauffman, J. M.; Litak, P. T.; Adams, J. K.; Henry, R. A.; Hollins, R. A. J. Heterocycl. Chem. 1992, 29, 1245.

9. (a) Tillyer, R. D.; Baudreau, C.; Tschaen, D.; Dolling, U.-H.; Reider, P. J. Tetrahedron Lett. 1995, 36, 4337; (b) Masui, M.; Shioiri, T. Tetrahedron Lett. 1998, 39, 5195; (c) Shimzu, M.; Tsukomoto, K.; Matsutani, T.; Fujisawa, T. Tetrahedron 1998, 54, 10265.

10. (a) Canpillo, N.; Garcia, C.; Goya, P.; Paez, J. A.; Carrasco, E.; Grau, M. J. Med. Chem. 1999, 42, 1698; (b) Fröhlich, L. G.; Kotsonis, P.; Traub, H.; TagaviMoghadam, S.; Al-Masoudi, M.; Hofmann, H.; Strobel, H.; Matter, H.; Pfleiderer, W.; Schmidt, H. H. H. W. J. Med. Chem. 1999, 42, 4108; (c) DeMeester, J. W. G.; Van del Plas, H. C.; Middelhoven, W. J. J. Heterocycl. Chem. 1987, 24, 441; (d) Mendoza, J. S.; Jagdmann, G. E., Jr.; Gosnell, P. A. Bioorg. Med. Chem. Lett. 1995, 5, 2211; (e) Balsamo, A.; Breschi, M. C.; Lapucci, A.; Macchia, B.; Martinotti, E.; Nencetti, S.; Nieri, P.; Orlandini, E. J. Med. Chem. 1989, 32, 856. 
11. Usami, K.; Isobe, M. Tetrahedron 1996, 52, 12061.

12. (a) Moorhoff, C. M.; Paquette, L. A. J. Org. Chem. 1991, 56, 703; (b) Katrook, M.; Ohno, M. Bull. Chem. Soc. Jpn. 1973, 46, 3474; (c) Boulet, C. A.; Hanseu, A. S. Phosphorus, Sulphur, Silicon Related Elements 1991, 57, 147; (d) Yates, P.; Wong, J.; McLean, S. Tetrahedron 1981, 37, 3357.

13. For $\alpha$-diketones, see: Lee, J. C.; Park, H. J.; Park, J. Y. Tetrahedron Lett. 2002, 43, 5661 and references cited therein.

14. (a) Basett, J.; Bensted, J.; Grzeskowial, R. J. Chem. Soc. A 1969, 2873; (b) Thakkas, N. V.; Bootwala, S. Z. Indian J. Chem., Sect. A 1995, 34A, 370; (c) Agarwal, S. K.; Jain, J.; Chand, S. Asian J. Chem. 2002, 14, 489; (d) Frederickson, M.; Grigg, R.; Thornson-Pett, M.; Redpath, J. Tetra- hedron Lett. 1997, 38, 7777.

15. Tanaka, K.; Toda, F. Chem. Rev. 2000, 100, 1025.

16. The reaction was run using $0.10-10.0 \mathrm{~g}$ of the ketone with no significant change either in yield or purity of the oximino ketone. Typical experimental procedure: $\mathrm{Me}_{3} \mathrm{SiCl}$ $(1.2 \mathrm{~g}, 11.0 \mathrm{mmol})$ was added slowly to the ketone in $5 \mathrm{~mL}$ of $\mathrm{CH}_{2} \mathrm{Cl}_{2}$ at $-20^{\circ} \mathrm{C}$ in a $50 \mathrm{~mL}$ two-necked flask fitted with a $\mathrm{CaCl}_{2}$ guard tube, followed by dry isoamyl nitrite (1.4 $\mathrm{g}, 12.0 \mathrm{mmol})$. The mixture turned blue and then yellow. After stirring for $30 \mathrm{~min}$ more, ether or $\mathrm{CH}_{2} \mathrm{Cl}_{2}(20 \mathrm{~mL})$ was added and the reaction worked up in the usual way. The product was eluted on a silica gel column using pet. ether (bp $50-55^{\circ} \mathrm{C}$ ) containing $5 \%$ ethyl acetate to get pure product. 